\title{
UM ESTUDO DAS CONTRIBUIÇÕES DE SCHOPENHAUER PARA A CIÊNCIA DA INFORMAÇÃO: O MUNDO COMO VONTADE E REPRESENTAÇÃO
}

\author{
A STUDY OF SCHOPENHAUER CONTRIBUTIONS FOR \\ INFORMATION SCIENCE: THE WORLD AS WILL AND \\ REPRESENTATION
}

\author{
Janailton Lopes Sousa \\ Rogério Aparecido Sá Ramalho
}

\begin{abstract}
RESUMO
Introdução: Arthur Schopenhauer foi um filósofo alemão do século XIX autor do livro intitulado 'O Mundo como Vontade e Representação', publicado originalmente em 1819, onde aborda a complexa relação entre representação e o modo como o homem interpreta a realidade. Objetivo: Analisar as contribuições de Arthur Schopenhauer, identificadas na obra 'O Mundo como Vontade e Representação', verificando aproximações com corpus teórico da Ciência da Informação, principalmente em relação aos trabalhos desenvolvidos por Wittgenstein (1968) e Dahlberg (1978), referentes ao estudo da Linguagem e Teoria do Conceito. Metodologia: A pesquisa enquadra-se como teórica, de caráter analítico e utilizou como procedimentos metodológicos atividades de revisão, análise e interpretação da literatura selecionada. Resultados: A partir do estudo realizado foi possível inferir que os trabalhos desenvolvidos por Wittgenstein (1968) e Dahlberg (1978) no âmbito da área de Ciência da Informação foram influenciados pela concepção de representação apresentada na obra de Schopenhauer, considerando que as representações fundamentam o entendimento humano sobre o funcionamento da realidade como se conhece, desenvolvidas como formas para codificar a natureza, e as relações entre os seres, em uma linguagem assimilável à razão. Conclusões: Schopenhauer oferece uma concepção de representação que pode ser incorporada no campo da Ciência da Informação, pois entende que os conceitos são elementos chave da representação, abarcando a relação sujeito e objeto, o conhecimento seria o resultado dessa relação e uma forma de representação do mundo.
\end{abstract}

\footnotetext{
a Mestrando do Programa de Pós-Graduação em Ciência da Informação da Universidade Federal de São Carlos (PPGCI-UFScar).

b Professor do Departamento de Ciência da Informação da Universidade Federal de São Carlos (UFSCar). Doutor pelo Programa de Pós-Graduação em Ciência da Informação pela Universidade Estadual Paulista (UNESP).
} 
Descritores: Representação do conhecimento. Teoria do conceito. Representação da Informação. Organização do Conhecimento. Schopenhauer.

\section{INTRODUÇÃO}

$\mathrm{O}$ ato de representar figura como um elemento primordial para compreender a condição humana e a complexa relação existente entre a realidade e o modo como o homem a interpreta. Ao longo da história da humanidade a Arte se caracterizou como uma das principais formas de representação, expressada de forma simbólica e particular, desejos, abstrações e os mais diversos sentimentos ou fatos que refletem toda uma sociedade.

Esta forma de representação foi amplamente difundida por meio de esculturas, pinturas e da escrita. A representação, nas esculturas obedece às leis da física que limitam sua concepção, na pintura o limite passa a ser a combinação das cores, todavia, ambos dizem respeito à imaginação ou estado de espírito de seu idealizador. Portanto as pinturas e esculturas começam estabelecer um tipo de linguagem com uma sintaxe visual, na qual é possível decifrar o que pode significar determinada obra artística.

Na escrita esta sintaxe é notória, aliada a semântica, que fornece suporte a interpretação de um texto. Estas propriedades oriundas da linguagem, fornecem os parâmetros de codificação e decodificação dos elementos representados por meio da escrita. Representar é uma das formas de externar as abstrações humanas, seja por meio da linguagem falada, escrita, simbólica, gestual, gráfica ou quaisquer outros tipos.

Arthur Schopenhauer foi um filósofo alemão do século XIX, que ficou conhecido pelo seu pessimismo filosófico, nasceu em 1788 na cidade de Gdańsk, na Polônia e faleceu em Frankfurt, Alemanha, aos 72 anos. Teve influência do idealismo transcendental de Immanuel Kant e inspirou o filósofo Friedrich Nietzsche, legado que marca sua influência na filosofia moderna.

O presente trabalho está vinculado a um projeto de pesquisa em andamento financiado pela FAPESP e CNPq, possui como objetivo analisar as contribuições de Arthur Schopenhauer, identificadas na obra 'O Mundo como Vontade e Representação', verificando aproximações com corpus teórico da 
Ciência da Informação, principalmente em relação aos trabalhos desenvolvidos por Wittgenstein (1968) e Dahlberg (1978), referentes ao estudo da Linguagem e Teoria do Conceito.

A pesquisa enquadra-se como teórica, de caráter analítico e utilizou como procedimentos metodológicos atividades de revisão, análise e interpretação da literatura selecionada. Para revisitar o pensamento de Schopenhauer, adotou-se os comentários de Mann (1955) para melhor entendimento das proposições apresentadas. Portanto utiliza o método qualitativo como requisito de análise, por uma perspectiva discursiva explicativa.

A representação possui o conceito como elemento de definição da estrutura que a compõem, partindo dessa concepção, a relação entre o sujeito e o objeto origina o conhecimento e o conceito é definido como sua unidade básica. Ao identificar os conceitos contidos na representação a linguagem entra em cena, como o parâmetro que ordena a apreensão do conhecimento humano.

Para explicitar esta relação é apresentada inicialmente as concepções principais de Schopenhauer sobre o que é representação e conceito, em seguida é iniciado um diálogo com Dahlberg (1978) sobre a percepção de conceito na Ciência da Informação, deste modo é possível dialogar com Wittgenstein (1968) sobre o uso da linguagem, tendo em vista que a Lógica é o elemento comum entre os três autores. Por fim, são apresentadas algumas considerações finais a respeito dessas concepções na perspectiva da Ciência da Informação.

Schopenhauer (2005) oferece uma definição de representação que se alinha às concepções encontradas na Ciência da Informação, principalmente no âmbito da Organização e Representação do Conhecimento, associada à teoria do conceito. Isto possibilita uma ampla discussão sobre linguagens e Sistemas de Organização do Conhecimento (SOC).

Os SOC são caracterizados por um sistema lógico expresso em determinada linguagem, que pode ser um conjunto de símbolos ou caracteres alfanuméricos que favorecem a ordenação conceitual de uma representação. Estas características são identificadas por meio desses autores nos seus respectivos campos de domínios, todavia percebe-se a convergência conceitual que se direciona para a Ciência da Informação. 


\section{MUNDO COMO REPRESENTAÇÃO}

Para referenciar este estudo, foi utilizada a obra "O mundo como vontade e como representação" tomo I, que encontra-se dividida em 4 livros, alternados com a tema representação e vontade. O Primeiro livro trata sobre a representação e sua subordinação a razão e as condições pelas quais são regidas a realidade (tempo, espaço e causalidade). O segundo livro aborda sobre a objetivação da vontade que levam a um pessimismo metafísico.

O terceiro livro recupera a discussão sobre representação, todavia independente do princípio da razão, por meio de uma intuição estética. Por fim o quarto livro retoma a discussão sobre vontade, com uma espécie de metafísica da ética, examinando o sentido das ações humanas. Na construção do escopo teórico foram priorizadas as concepções sobre representação e conceito explícitas no primeiro e no terceiro livro.

As representações compõem o universo humano tal como a habilidade de pensar, por isso Schopenhauer (2005) estabelece diferenças entre os tipos de representações, ou seja, ela pode ser intuitiva ou abstrata. As representações intuitivas estão atreladas a percepção do sujeito, já as abstratas constituem uma classe de representações, os conceitos, habilidade peculiar atribuída ao ser humano, nomeada pela razão.

Por se tratar de concepções abstratas, os conceitos existem ubiquamente, tratados como noções gerais sobre determinado objeto ou fenômeno, os conceitos são níveis categóricos do conhecimento humano elaborado para referenciar as representações.

O alto nível de abstração, não elimina a possibilidade de materializar um conceito, por exemplo, em figuras geométricas, como triângulos, quadrados e retângulos. Estas figuras geométricas não existem de fato na natureza, elas são resultados de um conglomerado de cálculos que definem sua forma, por meio da matemática é possível provar sua existência, no entanto esta se limita apenas na esfera abstrata, pois quando materializados tratam-se de representações deste modelo mental.

Os conceitos se comportam deste modo, pois armazenam sua essência 
na abstração, porém não impede sua conversão em objetos físicos, processos ou termos significativos. Logo, o conceito é resultado dessas percepções que se encontram no universo abstrato, deste modo a organização do conhecimento visa à construção de modelos de mundo que se constituem em abstrações da realidade (BRÄSCHER; CAFÉ, 2008).

Segundo Schopenhauer (2005) o conceito é abstrato, discursivo, inteiramente indeterminado no interior de sua esfera, determinado somente em seus limites acessível e apreensível por qualquer um, apenas dotado de razão. Além disso, comunicável através de palavras, sem ulterior mediação, completamente esgotável por sua definição. (SCHOPENHAUER, 2005).

Para explicitar essa concepção Schopenhauer (2005) afirma que o conceito se assemelha a um recipiente inanimado em que tudo o que é ali depositado realmente se encontra lado a lado, mas do qual também não podemos extrair mais (por juízos analíticos) do que nele depositamos (por reflexão sintética).

Segundo Schopenhauer (2005) o conceito é uma representação cuja consciência distinta e conservação ligam-se à palavra, não obstante, o conceito é por inteiro diferente tanto da palavra, à qual está conectado, quanto das intuições, das quais originou-se.

Ao partir da representação como o primeiro fato da consciência encontrase em Schopenhauer (2005) a sua essência ou sua forma primeira e fundamental, que é o sujeito e o objeto. A forma do objeto como princípio da razão em suas diversas figuras, cada uma das quais regem tão precisamente sua classe de representações, que no conhecimento de cada figura também se conhece a essência da classe inteira, pois esta como representação nada mais é senão aquela figura mesma.

Nestas classes de representações estão contidos os conceitos, os quais são entendidos como a referência ao fundamento do conhecimento, percebe-se que há uma intrínseca relação entre sujeito/objeto para representação, assim como conhecimento/conceito. O sujeito e o objeto são elementos que possui um relacionamento mútuo, a partir deste relacionamento é possível chegar à representação. 
A essência da representação é a explicação fundamental do conhecimento e dos conceitos, ora, a representação é senão o elo entre o cognoscível e a própria realidade orientada pelo espaço/tempo, logo, a razão possui apenas uma função, a formação de conceitos (SCHOPENHAUER, 2005). A representação, quando orientada pela razão permite sobretudo a formação de conceitos em sua constituição.

Os conceitos formam uma classe particular encontrada no espírito do homem, portanto, os conceitos permitem apenas pensar, não intuir. O que a razão recebe e comunica são conceitos abstratos, representações, os quais compreendem e representam os objetos do mundo efetivo. Essa ordenação lógica da representação torna-se manifesta por meio da linguagem.

A linguagem é um dos elementos chave neste processo, pois é explicitada por meio de conceitos, representações abstratas e universais não individuais, não intuitivas no tempo e no espaço (SCHOPENHAUER, 2005). Enquanto mecanismo usual da sociedade é utilizada desde épocas remotas, por meio de símbolos cujo significado recorria a processos factuais. Comumente associada ao processo de comunicação supera a simples transmissão de uma mensagem com valor lógico, carrega consigo uma noção de sentido a partir dos signos expressos.

Reconhecida pelo devir importado dos fatos sociais que transmutam as relações humanas, ou seja, sua mutabilidade acontece de modo associativo às atividades humanas, portanto se percebe a linguagem como um ato social, ação, fatos e a tessitura do conhecimento sobre a realidade percebida (WITTGENSTEIN, 2009). Esta concepção aproxima a linguagem das interações sociais e suas consequências, que podem gerar novos atos ou resultados.

A linguagem enquanto ação resgata algumas proposições de Ludwig Wittgenstein em sua segunda fase, apontada na Philosophische Untersuchungen, que a associa aos fatos que compõem o mundo, esta visão transmórfica da linguagem destaca sua participação vital no ciclo das ações humanas e como ela pode ser maleável no transcurso dos acontecimentos (WITTGENSTEIN, 2009). No entanto, adotam-se os conceitos apresentados sobre a linguagem em sua primeira fase, especificamente do Tractatus Logico- 


\section{Philosophicus.}

Dentre os benefícios da linguagem, encontra-se o processo de representação dos fatos por meio de palavras, que obedecem a regras lógicas de composição morfossintática e semântica. Essas composições estruturais da linguagem oferecem suporte para a construção de signos e sentido das proposições frasais dos sujeitos para o seu interlocutor. (WITTGENSTEIN, 1968).

Neste sentido é necessário observar o arranjo lógico das palavras, no que diz respeito à sintaxe, que propiciará a estruturação correta das palavras em determinada língua (WITTGENSTEIN, 1968). Assim como sua composição semântica, que vincula o valor lógico ao sentido expresso por meio dos signos, com isto apresentam-se os fundamentos basilares da conexão linguística entre os indivíduos.

No entanto, estes fundamentos não são suficientes para a transmissão de informações entre sujeitos, no que concerne à força ilocucionária que se insere na linguagem falada, escrita ou representada sob qualquer suporte, tangivel ou imaterial.

Portanto, a linguagem carrega algo de peculiar que por si só a sintaxe e a semântica não conseguem explicitar, o que autores como Wittgenstein apresentam como uma visão pragmática da linguagem, que considera essa variação da linguagem e sua vivacidade, alterando-se também de acordo com os contextos na qual está inserida.

O valor social da linguagem volta para os aspectos contextuais e as condições de uso, (re)significando, o que outrora fundamentava determinado conhecimento, propondo uma avaliação das condições de verdade em que estão imbricadas determinados conceitos que compunham o atomismo lógico, que é caracterizado pela divisibilidade do conhecimento em unidades simples no qual estaria fundamentado e a generalização conceitual das coisas (WITTGENSTEIN, 2009).

Esta relação entre conceito e linguagem é vinculada fundamentalmente pela razão, que possibilita a representação por meio de uma figura própria uma classe de representações. A linguagem é, pois um mecanismo desenvolvido pelo 
homem para exprimir suas abstrações de forma lógica e racional, sem ela, seria impensável conjecturar qualquer sequência concisa de signos que pudessem ser transmitidos.

Neste sentido, trata-se da comunicação abstrata do ser humano com o mundo, portanto o mundo não é senão a forma como o homem consegue assimilá-lo e representá-lo. De acordo com Schopenhauer (2005) a essência completa dos conceitos, ou da classe de representações abstratas, reside exclusivamente na relação que o princípio de razão exprime nelas, ora, como tal relação é o fundamento de conhecimento, segue-se que a representação abstrata possui sua essência inteira e exclusivamente, em relação com outra representação que é o seu fundamento de conhecimento.

Deste modo, um conceito possui uma relação guiada pela razão entre outros conceitos, não de forma infinita, pois os fundamentos de conhecimento findam em um conceito, estas representações expressas na forma de conceitos possuem relações entre os fundamentos da mesma classe, o que remonta a noção de domínio.

Logo, esta relação entre conceitos dizem respeito à um determinado domínio do conhecimento que é apresentado na forma de conceitos vinculados. O que na Ciência da Informação poderia ser apresentado na forma de vocabulários controlados. Esta concepção de conceitos vinculados é bastante similar à adoção de termos significativos que representam conceitos na elaboração de vocabulários para determinados domínios do conhecimento.

Schopenhauer (2005) explica que apesar dos conceitos possuírem essa característica de representar um objeto, nem sempre ele será a representação de uma representação, isto é, possuir sua essência inteira e exclusivamente em sua referência a outra representação. Existe a possibilidade de um conceito abranger mais de um objeto específico pela sua característica essencial que é a generalização.

[...] não por que é abstraído de muitos objetos, mas ao contrário, justamente por que a generalidade, ou seja, a não determinação do particular, é essencial ao conceito como representação abstrata da razão, apenas por isso, diversas coisas podem ser pensadas mediante um mesmo conceito. (SCHOPENHAUER, 2005, p. 89). 
Esta característica universal dos conceitos possibilita esse tipo de ação, no entanto um objeto não deve possuir dois conceitos distintos, pois um deles seria falso, portanto necessitaria de algum elemento comum para vinculá-lo ao objeto. Porque Schopenhauer (2005) explica que a esfera de um conceito tem algo em comum com a esfera de outros conceitos, ou seja, que em parte é nele pensado a mesma coisa que é pensado nos outros, e vice-versa conforme a figura 1. Essa relação entre os conceitos também pode ser expressa da seguinte forma:

a) As esferas de dois conceitos iguais possuem conceitos intercambiáveis expostos por um único círculo, a significar tanto um como outro;

b) A esfera de um conceito encerra no todo a esfera de outro conceito;

c) Uma esfera encerra duas ou mais esferas que se excluem e, ao mesmo tempo, preenchem a esfera;

d) Duas esferas encerram-se, cada uma, parte da outra;

e) Duas esferas estão contidas numa terceira; mas não a preenchem;

Figura 1 - Esferas de conceitos de Schopenhauer

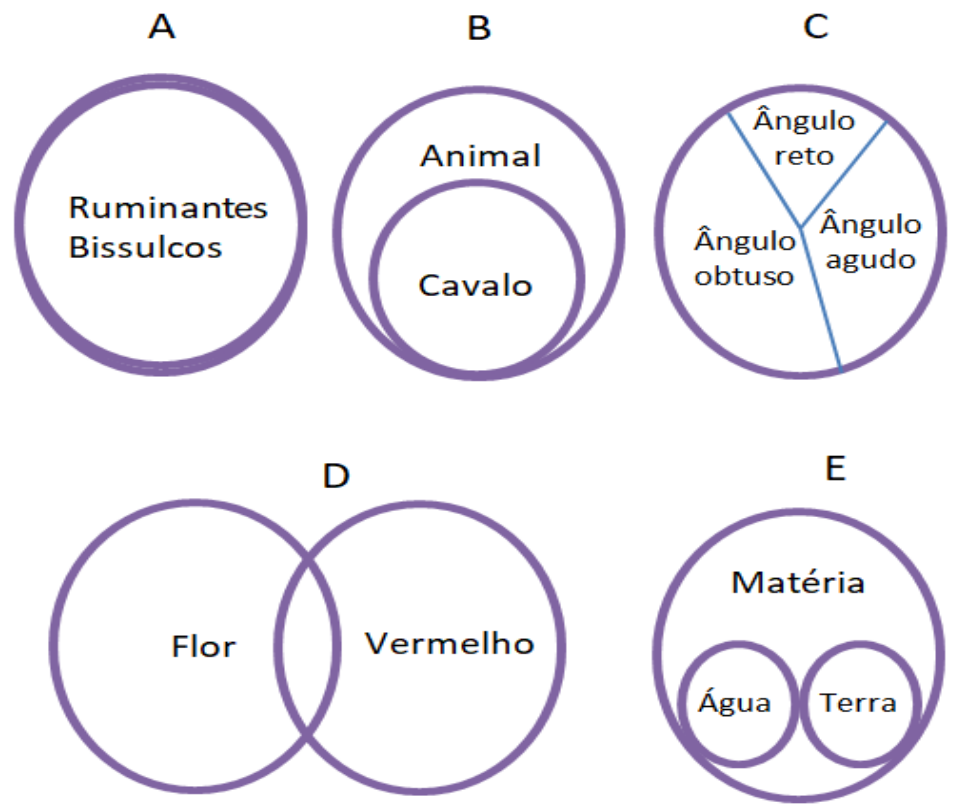

Fonte: Adaptado de Schopenhauer (2005)

Esse arranjo estrutural das esferas de conceitos recupera um princípio matemático encontrado na teoria dos conjuntos, onde é possível unir, 
interseccionar, conter ou não, pertencer ou não, diferenciar, complementar determinados números, entre os conceitos é possível aplicar semelhantes operações lógicas.

A ilustração A sugere que um que os conceitos são intercambiáveis, possuindo semelhanças, podem a aplicar-se de formas diferentes a mesmo objeto. A ilustração $b$ indica um tipo de hierarquização dos conceitos e que seus limites encerram-se em conceitos gerais.

A ilustração $C$ demonstra um tipo de de particionamento dos conceitos, que podem ser excludentes entre si, mas necessários para sua constituição, a ilustração $D$ é a forma mais simples de relacionamento, onde um conceito se intersecciona com outro.

A llustração E demonstra a capacidade de um conceito conter mais de uma esfera em sua estrutura, sem depender dessa aglomeração para que seja constituído. Ou seja, a existência de duas esferas não condiciona a existência do conceito.

Esta da visão das esferas de conceitos evidencia uma relação de conjuntos e subconjuntos, união e intersecção de conceitos, que pode ser consultado nos diagramas de Venn, por exemplo. Quando muitas esferas se arranjam dessa maneira, nasce uma longa cadeia de silogismos, esquemas de conceitos (SCHOPENHAUER, 2005).

Esta noção matemática não é mera coincidência, pois Schopenhauer (2005) cita a contribuição Leonhard Euler (1707-1783), que levou esse procedimento a bom termo usando círculos e por isso baseia-se nele. Não se sabe se ele estaria se referindo a teoria dos grafos desenvolvida a partir da resolução da resolução de um problema da matemática conhecido como as Sete pontes de Königsberg em 1736.

Isto quer dizer que essas esferas de conceitos submetem-se à lógica e matemática, portanto o conceito não é apenas um exercício de abstração, mas um refinamento da razão que se estrutura de forma coesa e universal, na linguagem dos escolásticos, que afirmavam: os conceitos são os universali post rem (SCHOPENHAUER, 2005).

Depreende-se que os conceitos permitem vários tipos de 
relacionamentos, que podem variar do simples compartilhamento de elementos comuns, quanto a inserção de conceitos individuais que obedecem a um tipo de subordinação aos conceitos gerais, característica transmitida na constituição de vocabulários controlados.

\section{TEORIA DO CONCEITO E LINGUAGEM}

Dentre os campos de estudo da Ciência da Informação, a Organização do Conhecimento tem ganhado notoriedade pela emergência e consolidação de suas teorias, dentre elas a Teoria do Conceito apresentada por Dahlberg, tornouse um dos principais alicerces na constituição de discussões que englobam o conhecimento tanto a nível teórico como prático.

O uso da Lógica para determinar um conceito é um recurso utilizado por Dahlberg (1978) na construção de sua teoria. Ao entender o conceito como unidade do conhecimento apresenta a definição precípua do que deve ser estritamente verdadeiro, portanto o conceito seria o substrato que resultaria da aplicação do método científico.

Para definir um conceito, além de utilizar um método e as primazias da Lógica é necessário identificá-lo pela ótica da linguagem. Pois o conhecimento fixou-se através dos elementos da linguagem. Neste sentido é possível construir tipos de relacionamento entre conceitos, assim como métodos de ordenação e a validação.

De acordo com Dahlberg (1978) novos conhecimentos apareceram com novos elementos linguísticos e também através destes tornaram-se mais claros e distintos. Além disso, o uso da linguagem a partir de uma perspectiva lógica proporciona um ambiente favorável para a definição de um conceito, pois condiciona uma tendência de verdade por meio de argumentos lógicos.

Com a ajuda das linguagens formais é possível construir enunciados a respeito tanto dos conceitos individuais como dos conceitos gerais. É em base a tais enunciados que se elaboram os conceitos relativos aos diversos objetos (DAHLBERG, 1978, p. 102). Logo, representar na linguagem algo que "contrarie as leis lógicas", ou seja, "[...] é perfeitamente possível representar um estado de coisas espacial contrário às leis da física, nunca, porém, contrário às leis da 
geometria." (WITTGENSTEIN, 1968, p. 61).

Dahlberg (1978) beneficia-se de uma lógica aristotélica para a construção de teoria carregada de silogismos, que segundo Schopenhauer (2005) pode conduzir a erros, sim, produzem paralogismos e sofismas que se originam muito mais facilmente e são muito mais difíceis de resolver do que a ilusão de uma intuição sensível.

Segundo Dahlberg (1978) todo enunciado sobre objetos contém um elemento do respectivo conceito. Ou seja, o conhecimento dos objetos dariam condições para definir um conceito geral, por que a definição real relaciona-se com o conhecimento do objeto. Em uma visão lógica quer dizer que, a definição de um conceito geral prever todos os outros conceitos associados a ele, pois estão relacionados a um objeto.

Nesta perspectiva, um conceito geral determina todos os outros que se relacionam com ele, não havendo necessidade de incluir nenhum a mais. Isto reforça a visão pragmática na construção de um conhecimento aplicado e aponta a necessidade de algumas revisões teóricas. Pois na visão de Wittgenstein (1968) na proposição está contido o signo, e o que no signo não vem expresso é indicado pela aplicação, o que os signos escondem, a aplicação exprime.

Wittgenstein (1968) assume que a partir das regras dos signos construímos uma proposição lógica e cada proposição da lógica é um modus ponens representado num signo, ou seja, sempre se pode conceber a lógica de tal modo que cada proposição seja sua própria prova.

Ao considerar o signo em uma proposição há traços essenciais (ligados às substâncias) e acidentais, que derivam da maneira particular de produzir o signo proposicional; essenciais, aqueles que sozinhos tornam a proposição capaz de exprimir seu sentido (WITTGENSTEIN, 1968).

Dahlberg (1978) destaca que sempre que diferentes conceitos possuem características idênticas deve-se admitir que entre eles existem relações. Neste sentido aponta as relações lógicas, hierárquicas (implicação), partitivas, de oposição (negação) e funcional (intersecção). Esta formas de relacionamentos são comumente encontradas nos Sistemas de Organização do Conhecimento (SOC). 
Apesar desse direcionamento que Dahlberg (1978) dá quando um conceito possui característica comum com outro, nota-se que ambos denotam sobre o mesmo objeto, sinonimamente ou em contextos diferentes. Wittgenstein (1968) aponta que na linguagem, corrente amiúde acontece, que a mesma palavra designa de modos diferentes, pertencendo a símbolos diferentes, ou ainda duas palavras, que designam de modos diferentes, são empregadas na mesma proposição.

A representação de conceitos na Ciência da Informação é expressa por meio de termos representativos que estão incorporados em determinado SOC, que pode ser um tipo de vocabulário controlado. Uma vez elencado tais termos é possível construir níveis de relacionamentos entre eles, que obedecem regras lógicas e semânticas.

O vocabulário controlado é uma das principais formas de eliminar os problemas recorrentes da linguagem, como homonímia e sinonímia, que podem gerar confusões em esferas conceituais. Portanto, as regras pelas quais um conceito é submetido são os principais fundamentos que orientam a construção de SOC e seus instrumentos.

Neste sentido, as esferas de conceitos de Schopenhauer (2005) e Dahlberg (1978) possuem intrínseca relação com os vocabulários controlados, à medida que discutem sobre a generalização e individualização dos conceitos, assim como as formas de relacionamentos entre eles. Isto quer dizer, que o pensamento de Schopenhauer está imbricado na Teoria do Conceito e nos instrumentos de representação abarcados pelos SOCs.

\section{CONSIDERAÇÕES FINAIS}

As representações fundamentam o entendimento humano sobre 0 funcionamento da vida e do mundo, são formas desenvolvidas para codificar a natureza e as relações entre os seres para uma linguagem assimilável à razão.

Os conceitos são elementos chave da representação, pois abarcam a relação sujeito e objeto e ao mesmo tempo expressa as abstrações contidas no consciente humano. Passível de aplicações lógicas os conceitos se aplicam como substratos para o uso de uma linguagem na qual é possível representar 
os objetos de todos os tipos, sejam eles materiais ou imateriais.

A lógica é uma disciplina que tem oferecido precioso suporte à formulação de conceitos, portanto é necessário apropriar-se de algumas noções que facilitem seu entendimento, assim como alguns princípios matemáticos que possuem valorosas explicações conceituais.

Assim, é neste sentido que Wittgenstein (1968) propõe o uso de uma linguagem simbólica que se submeta às regras da lógica para evitar algum tipo de confusão. A adoção de uma linguagem formal consideraria uma sintaxe lógica na construção das proposições cujos signos determinarão uma forma lógica.

Mesmo parecendo uma proposta instigante no que diz respeito à eliminação de problemas desse tipo, tal adoção não consideraria a evolução da linguagem, considerando padrões minimamente flexíveis a que seria submetida.

De acordo com Schopenhauer (2005) linguagem e escritura (os signos dos conceitos) possibilitam, todavia, que uma precisa informação chegue sobre cada coisa e cada relação, não importando quando e onde tenham ocorrido, porque poucos conceitos representam uma infinidade de coisas e estados.

Os conceitos possuem essa característica generalista, na qual é possível completar uma informação orientada pelo sentido lógico que o conceito expressa, logo, essa capacidade unívoca é essencial para o uso da linguagem na representação do conhecimento.

O mundo como representação seria apenas um modo como o percebemos individualmente, portanto isso varia por pessoa, contextos e outros parâmetros referências, como tempo e espaço. Pois a visão externa do objeto representado altera as formas de conhecimento sobre o próprio objeto, neste sentido que o conhecimento surge da relação entre o sujeito e o objeto.

\section{REFERÊNCIAS}

BRÄSCHER, M.; CAFÉ, L. Organização da informação ou organização do conhecimento? In: ENCONTRO NACIONAL DE PESQUISA E PÓSGRADUAÇÃO EM CIÊNCIA DA INFORMAÇÃO, 9., 2008, São Paulo. Anais... São Paulo: Ancib, 2008.

DAHLBERG, I. Teoria do conceito. Ciência da Informação, Rio de Janeiro, v. 7, n. 2, p. 101-107, 1978. 
MANN, T. O Pensamento vivo de Schopenhauer. Tradução de Pedro Ferraz do Amaral. São Paulo: Livraria Martins Editora, 1955.

SCHOPENHAUER, A. O mundo como vontade e representação. Tradução de Jair Barboza. São Paulo: UNESP, 2005.

WITTGENSTEIN, L. Philosophical Investigations. Wiley-Blackwell, 2009.

WITTGENSTEIN, L. Tractatus Logico-Philosophicus. Tradução de José Arthur Giannotti. São Paulo: Companhia Editora Nacional, 1968.

\title{
A STUDY OF SCHOPENHAUER CONTRIBUTIONS FOR INFORMATION SCIENCE: THE WORLD AS A WILL AND REPRESENTATION
}

\begin{abstract}
Introduction: Arthur Schopenhauer was a nineteenth-century German philosopher author of the book entitled 'The World as Will and Representation', originally published in 1819, which addresses the complex relationship between representation and the way man interprets reality. Objective: To analyze the contributions of Arthur Schopenhauer, identified in the work 'The World as Will and Representation', verifying approximations with the theoretical corpus of Information Science, mainly in relation to the works developed by Wittgenstein (1968) and Dahlberg (1978) study of Language and Concept Theory. Methodology: The research fits as theoretical, analytical character and used as methodological procedures activities of review, analysis and interpretation of the selected literature. Results: From the study carried out it was possible to infer that the works developed by Wittgenstein (1968) and Dahlberg (1978) in the scope of the Information Science area were influenced by the conception of representation presented in Schopenhauer's work, considering that the representations base the human understanding about the functioning of reality as it is known, developed as ways to encode nature, and relations between beings, in a language assimilable to reason. Conclusions: Schopenhauer offers a conception of representation that can be incorporated into the field of Information Science, since it understands that concepts are key elements of representation, since they encompass the subject and object relationship, knowledge would be the result of that relationship and a form of representation of the world.
\end{abstract}

Descriptors: Representation of knowledge. Theory of the concept. Representation of Information. Organization of knowledge. Schopenhauer.

\section{UN ESTUDIO DE LAS CONTRIBUCIONES DE SCHOPENHAUER PARA LA CIENCIA DE LA INFORMACIÓN: EL MUNDO COMO VOLUNTAD Y REPRESENTACIÓN}




\section{RESUMEN}

Introduction: Arthur Schopenhauer fue un filósofo alemán del siglo XIX autor del libro titulado 'El Mundo como Voluntad y Representación', publicado originalmente en 1819, donde aborda la compleja relación entre representación y el modo en que el hombre interpreta la realidad. Objetivo: Analizar las contribuciones de Arthur Schopenhauer, identificadas en la obra 'El Mundo como Voluntad y Representación', verificando aproximaciones con corpus teórico de la Ciencia de la Información, principalmente en relación a los trabajos desarrollados por Wittgenstein (1968) y Dahlberg (1978) el estudio del Lenguaje y la Teoría del Concepto. Metodología: La investigación se encuadra como teórica, de carácter analítico y utilizó como procedimientos metodológicos actividades de revisión, análisis e interpretación de la literatura seleccionada. Resultados: A partir del estudio realizado fueron inferir que los trabajos desarrollados por Wittgenstein (1968) y Dahlberg (1978) en el ámbito del área de Ciencia de la Información fueron influenciados por la concepción de representación presentada en la obra de Schopenhauer, considerando que las representaciones fundamentan el " entendimiento humano sobre el funcionamiento de la realidad como se conoce, desarrolladas como formas para codificar la naturaleza, y las relaciones entre los seres, en un lenguaje asimilable a la razón. Conclusiones: Schopenhauer ofrece una concepción de representación que puede ser incorporada en el campo de la Ciencia de la Información, pues entiende que los conceptos son elementos clave de la representación, pues abarcan la relación sujeto y objeto, el conocimiento sería el resultado de esa relación y una forma de representación del mundo.

Descriptores: Representación del conocimiento. Teoría del concepto. Representación de la Información. Organización del Conocimiento. Schopenhauer. 